\title{
Single port laparoscopic repair of incarcerated ventral hernia
}

\author{
Re: Laparoscopic repair of incarcerated ventral abdominal wall hernias, \\ Shah RH et al. (2008) Hernia 12(5):457-463
}

\author{
E. MacDonald $\cdot$ K. Pringle $\cdot$ I. Ahmed
}

Received: 13 January 2009 / Accepted: 23 February 2009 / Published online: 24 March 2009

(C) Springer-Verlag 2009

\section{Dear Editor,}

We read with great interest the paper by Shah et al. [1] describing the feasibility of laparoscopic repair of incarcerated ventral hernia.

We wish to report what we believe to be the first reported case using a single port to carry out this procedure.

The patient was a 45-year-old female who presented as an emergency with a 7-day history of a painful, tender and irreducible ventral hernia situated just above the umbilicus. She had undergone previous laparoscopic surgeries carried out using infra and supra umbilical approaches. The hernia was very tender and irreducible, measuring $5 \times 6 \mathrm{~cm}$ in size. She had no signs of intestinal obstruction. We repaired the hernia urgently using a 3-channel flexible single port placed in the left flank. The port was positioned midway between the anterior superior iliac spine and the costal margin. It was inserted using an open 12-mm muscle splitting incision placed in a stria already present in the skin to hide the scar. Straight standard instruments were used to dissect out the contents of the hernia, which consisted of fat from the falciform ligament, preperitoneal fat and omentum. The falciform ligament was dissected above the $3 \mathrm{~cm}$ defect in the midline using straight hook diathermy. This allowed placement of a covered composite mesh $(15 \mathrm{~cm} \times 15 \mathrm{~cm}$ in size) to cover the hernia defect. This was fixed with two sutures and multiple absorbable tacks. The port site wound was closed with 1 PDS under vision. The operating time was $40 \mathrm{~min}$. There were no intra-/post-operative complications. The patient was discharged within $24 \mathrm{~h}$.

We agree with Shah et al. that laparoscopic repair of irreducible ventral hernias is feasible. It may also be done using a single port and single incision $(12 \mathrm{~mm})$. This will result in less scarring and quicker recovery. The single port insertion using open cut down is safe and leaves only a single fascial wound to close.

We await with interest comments from readers.

Yours faithfully.

Conflict of interest statement None.

\section{References}

1. Shah RH, Sharma A, Khullar R, Soni V, Baijal M, Chowbey PK (2008) Laparoscopic repair of incarcerated ventral abdominal wall hernias. Hernia 12:457-463 